\section{The Relationship Regulator: a buyer-supplier collaborative performance} measurement system

\section{Introduction}

Over the years there has been a generalized tendency to increase management vision and control, with companies seeking to control over inter-firm processes and relationships. Several authors have therefore suggested that traditional intra-organizational performance measurement systems (PMSs) need to be broadened, with the development of external supply chain PMSs (SCPMSs), crossing company boundaries (Gunasekaran et al. 2004; Chae et al. 2009; Gunasekaran and Kobu, 2007). Easier said than done.

Three factors need to be considered in nowadays business environment. First, supply chains (SCs) are becoming more and more fuzzy: rather than being mutually exclusive chains, they appear as interconnected and overlapping networks, where companies are immersed and linked through diverse types of relationship (Lambert and Pohlen, 2001; Rice and Hoppe, 2001). Focus and choice is essential when extending the measurement process beyond company boundaries, yet often complex. Always bear in mind the following question: "which are the key performance that matters for this specific SC partner?" Second, organizational skills are critical to design and take full advantage of a SCPMS. Although purchasing, supply chain and customer service functions have increased their managerial capabilities in recent times (Luzzini and Ronchi, 2016), they still rarely display and follow formal strategies (Hesping and Shiele, 2015). Third, a reliable and robust information system infrastructure is critical for a successful implementation of an external SCPMSs (Nudurupati et al., 2011). This requires technological knowledge, resources and investments in order to tailor the ICT systems to the company specificities.

In the last fifteen years, internal PMS literature has progressively moved from measurement system design to its implementation (Bourne et al., 2000; Bourne et al., 2002), use (Henri, 2006; Koufteros et al., 2014) and review (Braz et al., 2011). External SCPMSs literature has not experienced this evolution yet. Contributions are still strongly focused on the "what to measure issue", with a profusion of studies on which performance dimension to tackle (Kannan and Tan, 2002; Gunasekaran et al., 2004) and how to select relevant metrics (Cai et al., 2009; Agarwal et al., 2006). Besides, in most cases only the point of view of the buyer company evaluating its suppliers is considered, thus neglecting two elements: first, suppliers do measure performance of their customers by means of customers PMSs in many cases; second, actively considering the perspectives of both parties is critical to evaluate the effectiveness of the measurement tool. Finally, suppliers PMSs are generally viewed as diagnostic tools for monitoring, which the buyer puts in place to control its supply base with an evaluation purpose (Henri, 2006). The role of the measurement system in enabling mutual collaboration on performance, has not been thoroughly investigated so far (Koufteros et al., 2014; Melnyk et al. 2014).

The present study aims at challenging limitations of extant literature by proposing an innovative framework allowing buyer-supplier collaboration on mutual performance. We call it the Relationship Regulator (RelReg). The RelReg is explained all along its lifecycle elements (i.e. design, implementation, use and review phases), highlighting the role of both parties at each step.

The remainder of the paper is organized as follows: section two reports a review of extant scientific literature on the subject, addressing the streams of SCPMS, supplier evaluation and buyer-supplier relationship evaluation. Section three resumes the goal of the paper and the methodology adopted. In section four the RelReg is described in its constituent elements, highlighting both the design features and guidelines to follow along the implementation, use and review. Section five reports a critical discussion of the pros and cons of the RelReg. Conclusions end the paper.

\section{Performance measurement in the supply chain}

Starting from the late nineties (Van Hoek, 1998; Beamon, 1999), several authors in the academic literature have reported on studies of the development of PMSs addressing the evaluation of activities outside legal company boundaries. Hald and Ellegaard (2011) identifies three converging and overlapping streams of research, according to the scope of the system they address and the labels used: SCPMS tackling SC processes and practices (Gunesakaran et al., 2001 - 2004; Angerhofer and Angelides, 2006); supplier evaluation focusing on first tier suppliers (Simpson et al., 2002; Kannan and Tan, 2002; Luzzini et al., 2014); buyer-supplier relationship assessment, focusing on soft aspects like mutual commitment, integration, trust etc. (Giannakis, 2007; Ramanathan et al., 2011). For the sake of clarity it is worth providing precise definitions of recurrent labels in this paper. Influenced by Neely et al., (1995) definition of PMS, we refer to external SCPMS as a set of metrics used to quantify the efficiency and effectiveness of inter-firm processes and relationships. From the perspective of a business-to-business company, we can eventually distinguish between suppliers PMSs (set of metrics used to quantify the efficiency and effectiveness of suppliers' actions) and customers PMSs (set of metrics used to quantify both the efficiency and effectiveness of customers' actions).

Within the broad area of external SCPMS, most studies address the pattern of the evaluating buyer company, adopting suppliers PMS to control and orchestrate its supply base. This implicitly uncovers two main limitations: first, the lack of insights on customers PMSs put in place by supplier companies to monitor their buyers performance; apart from a few comprehensive SCPMS tackling also downstream processes and relationships (e.g. Gunasekaran and Kobu, 2007; Bullinger et al., 2010), 
customers PMS are largely neglected, yet often used by companies' customer service functions. Second, the paucity of contributions reporting also the point of view of the evaluated company; in assessing the effectiveness of the measurement process, it seems logical to take into account both the evaluating and evaluated company perspectives should be taken into account. On this behalf it is interesting to note that the few studies jointly reporting the dyadic perspective, actually highlight a strong dichotomy of perceptions between the two parties. Purdy et al., (1994) and Purdy and Safayeni (2000) report three main conclusions: (1) the majority of suppliers feel that their effectiveness is not accurately reflected in the evaluation, which seems more a test of how much their companies look like the buyer. (2) The evaluating buyer company did not utilise the information gathered through the audit process properly, because in the end their decisions were based only on price savings. (3) Suppliers believe that the score reported is driven by bargaining power rules and does not result from a formal and objective evaluation process. Hald and Ellegaard (2011) by means of two longitudinal case studies investigate how performance measurement information, travelling between the evaluating buyer and the evaluated suppliers, is shaped and reshaped in the evaluation process. The authors highlight that a harsh dialectic often arises between the two parties on the suppliers PMS put in place.

Another characteristic of extant scientific literature on external SCPMSs is the primary focus on the design process. Various models have been proposed over the years, like the SC balanced scorecard (Brewer and Speh, 2000; Bhagwat and Sharma, 2007); the SCOR framework (Sellitto et al., 2015; Gunasekaran et al., 2004; Akyuz and Erkan, 2010); process-based approach (Chan and Qi., 2003); suppliers' scorecard (Kannan and Tan, 2002). In parallel algorithms and methodologies for metrics selection and prioritization have been proposed like the analytic hierarchy process (AHP - Cai et al., 2009; Cho et al., 2012), fuzzy AHP (Hong and Zhong-Hua, 2013), Analytic Network Process (ANP - Agarwal et al., 2006). On the other hand, empirical investigation on the effectiveness of previous frameworks and the analysis of other phases within their lifecycle (i.e. the implementation, use and review), are definitely lacking. Nonetheless, several contributions on internal PMSs acknowledge that the implementation (Bourne et al., 2000; Bourne et al., 2003), use (Henri, 2006; Koufteros et al., 2014) and review (Lohman et al., 2004; Braz et al., 2011) of a PMS are crucial determinants of its success, as important as a proper design.

\section{Research design and objectives}

Reviewing extant scientific literature, several signals suggest that the traditional pattern entailing the buyer company evaluating its suppliers appears as a highly constraining and limiting scheme. First the fact that suppliers do actively measure some performance of their customers (e.g. forecasting accuracy, payment timeliness) is not taken into account. Second, it seems to prevent the development of relational capabilities (such as mutual commitment, social capital), which strongly affects the effectiveness of the measurement process.

Within this paper we challenge this unidirectional and diagnostic paradigm, by proposing the Relationship Regulator (RelReg), an innovative framework aimed at stimulating a collaborative buyer-supplier performance measurement and management. The RelReg entails a dyadic joint measurement of balanced performance dimensions, some addressing the supplier, some addressing the buyer and some others addressing both parties. The logic behind is to use the measurement tool to enable collaboration and continuous improvement on relationship performance. Acknowledging the critical role of all the phases within the SCPMS lifecycle, after presenting the RelReg design features, we highlight the key activities to be performed when implementing, using and reviewing the tool (Gutierrez et al., 2015; Bititci et al., 2006)

It is a conceptual theory building paper, aimed at providing a smart tool ready to be used by practitioners. The review of extant literature on external SCPMS and the participation to severa practitioners' workshops as well as applied research projects on topics spanning from purchasing to performance measurement and management, guide the development of the framework constituent parts. Internal PMS lifecycle literature has been addressed to identify critical elements along the implementation, use and review phases. These activities have then been shaped coherently with the collaborative logic and the buyer-supplier scenario of the RelReg.

\section{Framework development}

In this section the Relationship Regulator is described along all the phases of its lifecycle. The first paragraph deals with the preliminary activities managers should take care of before setting a RelReg, being selecting the right partners to propose the project and formalize a relationship strategy. The second paragraph reports the RelReg constituent features, highlighting the performance dimensions to tackle and the design process. The third paragraph finally presents the main activities the buyer and the supplier should take care of along the implementation, use and review phases.

4.1 Antecedents of RelReg adoption

It is a common thought in operations management literature that competition is no longer between companies, but among supply chains, leading to the concept of supply chain based competition (Zhang, 2006; Qi et al., 2011). This is a critical concept per se, often treated superficially by referring to misleading formulas like the "supply chain vs supply chain" game. In most industries (e.g. consumer goods, consumer electronics, pharmaceutical, automotive etc.), competing supply chains 
appear more like interconnected or overlapping networks, than mutually exclusive chains of companies enrolled in a tier vs tier competition. Companies are nodes in fuzzy enterprise networks more than tiers in straight SCs: in this context strategic SCM practices could be exploited in order to create privileged path, thus achieving sustainable competitive advantage ( $\mathrm{Li}$ et al., 2015). The management of buyer-supplier relationships is therefore essential for achieving superior performance. Our effort to develop a buyer-supplier collaborative PMS is a concrete attempt to orientate buyersupplier dyad to increasing collaboration and continuous improvement.

A first aspect to consider is that as SCs become increasingly complex, companies are likely to interact with a lot of external partners. From the RelReg sponsor perspective (either a buyer or a supplier) is therefore of vital importance to carefully select the right SC partner to engage. A structured approach to portfolio management is therefore a key antecedent to succeed. Strategic relevance of the partners, current relationship capabilities in place, technical feasibility are some of the factors that should be taken into account. Taking from granted a high commitment from both parties involved, is then of fundamental importance to define a formal buyer-supplier relationship strategy that the RelReg should operationalize (Kaplan and Norton, 2010; Hesping and Shiele, 2015). The relationship strategy formalization should be the synthesis of a shaping and reshaping process of the two parties own strategies. It is of primary importance that the buyer and the supplier eventually agree on a limited set of strategic objectives, acting as the basement of their relationship.

To conclude developing a RelReg is a game of "focus and choice". Focus on your urgent SC needs and choose the right SC partner to engage in the project, through a mature portfolio management approach. Then focus on both parties needs within the specific relationship and choose a limited number of agreed goals to pursue.

4.2 The RelReg: design features

The essence of the RelReg is to enable collaboration within the buyer-supplier performance measurement and management process. The implicit logic of traditional external SCPMS (Simpson et al., 2002; Kannan and Tan, 2002) can be resumed in the following statement: "autonomously measuring something to evaluate someone". The RelReg turns this logic into: "joint measuring something to collaborate on mutual performance". In other words, we shift the logic of the external SCPMS from a tool for evaluation to a tool for collaboration (Giannakis, 2006). To put this statement into practice, we should facilitate the rising of collaboration all along the RelReg lifecycle, starting from its design characteristics. Figure 1 shows the RelReg dashboard.
Figure 1: RelReg dashboard: an illustrative example of the model

\begin{tabular}{|c|c|c|c|}
\hline \multicolumn{2}{|c|}{ UNIT OF ANALYSIS } & SUPPLIER & BUYER \\
\hline \multirow{3}{*}{$\begin{array}{l}\text { FINANCIAL } \\
\text { DIMENSION } \\
\text { "To achieve financial value } \\
\text { from this relationship, what } \\
\text { parameters should be } \\
\text { optimized?" }\end{array}$} & $\begin{array}{l}\text { BUSINESS } \\
\text { RELATIONSHIP }\end{array}$ & Revenue growth & Extra-savings \\
\hline & \multirow[b]{2}{*}{$\begin{array}{l}\text { TRANSACTIONAL } \\
\text { COSTS }\end{array}$} & Total cost of sales & Total cost of ownership \\
\hline & & \multicolumn{2}{|c|}{ Distribution costs } \\
\hline \multirow{7}{*}{$\begin{array}{l}\text { OPERATIVE } \\
\text { PROCESSES } \\
\text { "To ensure routinely } \\
\text { operational excellence, } \\
\text { which SC operational } \\
\text { activities should be } \\
\text { optimized?" }\end{array}$} & ORDER CYCLE & \multicolumn{2}{|c|}{ Agreed Order Fulfillment } \\
\hline & Order & $\begin{array}{l}\text { Order Fill Rate, Order } \\
\text { Lead Time }\end{array}$ & $\begin{array}{l}\text { No of Urgent Orders, } \\
\text { order variability }\end{array}$ \\
\hline & Delivery process & $\begin{array}{l}\text { Punctuality index } \\
\text { Flexibility index } \\
\text { Reactivity index } \\
\end{array}$ & \\
\hline & Invoicing & $\begin{array}{l}\text { Invoicing Accuracy, } \\
\text { Invoicing Timeliness }\end{array}$ & \\
\hline & Payment & & $\begin{array}{c}\text { Payment Timeliness } \\
\text { Documentation accuracy }\end{array}$ \\
\hline & $\begin{array}{l}\text { NEW PRODUCT } \\
\text { DEVELOPMENT }\end{array}$ & \multicolumn{2}{|c|}{$\begin{array}{l}\text { Product development time } \\
\text { No of new products developed per year }\end{array}$} \\
\hline & $\begin{array}{l}\text { TRACEABILITY AND } \\
\text { STOCK CONTROL }\end{array}$ & \multicolumn{2}{|c|}{ Inventory level, Security Stocks Level, } \\
\hline \multirow{3}{*}{$\begin{array}{l}\text { PLANNING } \\
\text { PROCESSES } \\
\text { "To achieve superior } \\
\text { coordination, which } \\
\text { planning process must we } \\
\text { excel at?" }\end{array}$} & DEMAND PLANNING & & $\begin{array}{l}\text { Forecast Accuracy, } \\
\text { Forecast Variability }\end{array}$ \\
\hline & $\begin{array}{l}\text { PRODUCTION } \\
\text { PLANNING }\end{array}$ & $\begin{array}{l}\text { Actual Versus Planned } \\
\quad \text { Production }\end{array}$ & \\
\hline & $\begin{array}{l}\text { DISTRIBUTION } \\
\text { PLANNING }\end{array}$ & $\begin{array}{l}\text { Changes Entity, Changes } \\
\text { Frequency }\end{array}$ & \\
\hline $\begin{array}{l}\text { PRODUCT/SERVICE } \\
\text { EXCHANGED } \\
\text { "To add value for the final } \\
\text { customer, which quality } \\
\text { target should respect the } \\
\text { good exchanged?" }\end{array}$ & $\begin{array}{l}\text { QUALITY-BASED } \\
\text { PERFORMANCE }\end{array}$ & $\begin{array}{l}\text { Quality rate, } \\
\text { Number of defects }\end{array}$ & \\
\hline \multirow{2}{*}{$\begin{array}{l}\text { RELATIONSHIP } \\
\text { INTANGIBLE } \\
\text { CAPABILITIES } \\
\text { "To continuously improve } \\
\text { our relationships, which } \\
\text { capabilities should we } \\
\text { develop?" }\end{array}$} & SOCIAL CAPITAL & \multicolumn{2}{|c|}{$\begin{array}{c}\text { Mutual trust } \\
\text { Goal alignment } \\
\text { Number of meetings } \\
\text { Perceived value of the relationship }\end{array}$} \\
\hline & $\begin{array}{l}\text { INFORMATION } \\
\text { CAPITAL }\end{array}$ & \multicolumn{2}{|c|}{$\begin{array}{l}\text { Exploitation of collaborative platforms } \\
\text { Digitalization degree } \\
\text { Information quality } \\
\text { Information timeliness }\end{array}$} \\
\hline
\end{tabular}

The metrics reported in the RelReg above are just examples: the set of metrics to select within each category is strictly dependent upon the strategic goals of the relationship and the availability of 
data. The performance category introduced are deriving both from literature (Simpson et al., 2002 Kannan and Tan, 2002; Luzzini et al., 2014) and from panel of experts' workshops and interviews joined by the authors A deeper analysis follows, highlighting the core questions animating debate with panel of experts on each dimension.

- Financial dimension. To achieve financial value from the relationship, which parameters should be optimized? Notwithstanding the corporate strategy, profitability is ultimately the key objective of every profit-oriented company. Empirical evidence highlights that financial strategies are simple; companies can make more money by: (1) selling more; (2) spending less. Any programs put in place (and strategic buyer-supplier partnership are no exception) creates more value for the company only if it leads to selling more or spending less. Thus, the company's financial performance gets improved through two basic approaches - revenue growth and productivity. Considering the buyer-supplier relationship within the RelReg, the buyer would be primarily compelled to lower the total "cost of ownership" of acquiring goods/service from the supplier. The supplier instead would be interested to lower the total cost of sales and to increase the revenues within the specific customer relationship

- Operational processes. To ensure routinely operational excellence, which SC processes should be optimized? Operational processes sustain the daily flows of materials, information, documentation and money between the buyer and the supplier (Kaplan and Norton, 1996). Depending upon the buyer-supplier strategy, more emphasis could be given to efficiency or effectiveness. Depending upon the buyer-supplier processes in place, the unit of analysis is modeled.

- Planning processes. To achieve superior coordination, which planning process must we excel at? Mutual and anticipated visibility of demand, production and distribution plans is at the basis of interface process coordination. Monitoring the accuracy of these plans will stimulate a continuous improvement in the overall planning processes, which could eventually result in operational improvement (Gunasekaran et al., 2001-2004)

- Product/service quality performance. To add value for the final customer, which quality target should respect the product/service exchanged? The overall quality of the product/service supplied is critical to add value along the supply chain and deliver something appealing for the end consumer (Simpson et al., 2002; Kannan and Tan, 2002).

- Relationship intangibles capabilities. To sustain our relationship, which capabilities should we develop? This dimension identifies the intangible assets that are important to stimulate and fuel mutual collaboration. We distinguish between social capital and information capital. The former relies in the degree of integration and mutual trust characterizing the relationship between the two parties. The latter identifies the availability of information system, networks and infrastructure required to support the buyer-supplier strategy. Qualitative metrics based on Likert scale questionnaire submitted to both the buyer and the supplier company could be used (Cousins et al., 2008)

Within the five categories identified, we coherently distinguish between metrics addressing the supplier's performance, metrics addressing the buyer's performance and transversal metrics jointly addressing both parties. Each metric in the RelReg should be exploded according to the paradigm proposed in the Balanced Scorecard (Kaplan and Norton, 1996) and re-adapted coherently with the presence of two actors. Figure 2 reports all the information to be defined for each metric.

\begin{tabular}{|c|c|c|c|c|c|c|}
\hline \multirow{2}{*}{$\begin{array}{l}\text { Strategic } \\
\text { relationship } \\
\text { objective }\end{array}$} & \multirow[t]{2}{*}{ Measures } & \multicolumn{3}{|l|}{ Target } & \multicolumn{2}{|l|}{ Initiatives } \\
\hline & & $\begin{array}{l}\text { Joint } \\
\text { definition }\end{array}$ & $\begin{array}{l}\begin{array}{l}\text { Supplier } \\
\text { definition }\end{array} \\
\end{array}$ & $\begin{array}{l}\text { Buyer } \\
\text { definition }\end{array}$ & Supplier & Buyer \\
\hline $\begin{array}{l}\text { Improve } \\
\text { delivery } \\
\text { performance }\end{array}$ & $\begin{array}{l}\text { Punctuality } \\
\text { index = No of } \\
\text { orders line } \\
\text { delivered on } \\
\text { time on total no }\end{array}$ & & & $\begin{array}{l}\square \\
95 \%\end{array}$ & $\begin{array}{l}\text { Planning } \\
\text { optimization }\end{array}$ & $\begin{array}{l}\text { Forecast } \\
\text { improvement }\end{array}$ \\
\hline
\end{tabular}

Figure 2: metric definition table - an example

First the strategic objective underneath should be stated as well as the precise measures on which the buyer and the supplier have to converge. Then the target should be included, identifying which actor defines it. Finally, a set of initiatives aimed at achieving the target, have to be listed: in most cases (especially when dealing with SC operational and planning processes or relationship capabilities) even if a certain performance is evaluating just one actor (either the supplier or the buyer), also the relationship partner could provide its support to improve the performance. The punctuality index as reported in Figure 2 is a good example: the supplier is the main responsible and should act on his delivery planning process and in the downstream transportation operations to improve the performance. On the other hand, also the buyer company could provide an active support, for example by improving its forecasts or optimizing the inbound logistics operations. Generally speaking, it is essential that both actors involved jointly managed various steps of the RelReg adoption

4.3 Implementing, using and reviewing the RelReg 
From internal PMS literature we know that most performance measurement and management projects fail because they are poorly implemented, use and review, rather than poorly designed (Bourne et al., 2003). In order to make the RelReg as a "ready to adopt" tool in the hands of practitioner, it is worth reporting in this research which are the main elements to consider within each phases of the PMS lifecycle and how should they be shaped when applying to a buyer-supplier PMS as the RelReg.

Once the RelReg is designed, it should be implemented. The implementation phase entails all the procedural steps enabling measurements to be made regularly (Bourne et al., 2000; Bourne et al., 2002; Bourne et al., 2003): data collection and integration, performance measures calculation and reporting management. In the RelReg these basic steps should be shaped coherently with the presence of two actors. Due to the existence of metrics addressing the buyer and metrics addressing the supplier, the primary data collection naturally involves the two parties. Each part is initially responsible to provide reliable data, either qualitative or quantitative, and to rigorously calculate the performance measures. The reporting phase is particularly important in enabling the collaborative approach on mutual performance, the fundamental logic behind the RelReg. A complete visibility on mutual performance agreed on the RelReg should be allowed. The frequency of the reporting depends upon the industry and the timing of the mutual flows between the buyer and the supplier. The management information systems are critical to the success of PMS implementation (Nudurupati et al., 2011; Ho, 2007), particularly in data collection, analysis, presentation and dissemination (Neely, 1999). In the RelReg case, they should enable an efficient and effective integration of the two parties; MIS technology innovation like web based or cloud platform for data sharing could be exploited.

The way the PMS is used ultimately defines its purpose and the expected outcome from the adoption. Using a PMS implies activities like feedback management, discussion on performance reported, improvement plans design, contract and incentives management. The most referred framework describing the PMS use is the diagnostic vs interactive paradigm (Henri, 2006). The diagnostic use reflects a traditional top-down feedback approach. Measures are used to unilaterally track progress towards goals, monitor results, compare outcomes to expectations, and drive rewards mechanisms accordingly. The interactive use reflects a bi-directional role of the PMS, which enables discussion on results and fosters continuous improvement, while in the meantime, improving functional integration. The RelReg, as a collaborative buyer-supplier PMS, is more oriented towards an interactive use. However this should not relax the constant effort on continuous improvement: roles, responsibilities and consequences should be clear from the beginning.

The last step of the PMS lifecyle entails the review of the set of metrics adopted, aimed at keeping the PMS constantly aligned with a changing strategy (Braz et al. 2011). Reviewing the RelReg first implies to detect changes in the relationship strategies and coherently reformulate the goals of the collaboration. Contextual variables (like technological innovations, changing in customers' needs, competitors' actions, new industry regulations etc.) or company specific (changes in the business strategy, new supplies need) could lead to review the buyer-supplier relationship strategy. Then, coherently with the new goals, the design features of the measurement tool should be updated, by introducing new metrics, or changing the targets and initiatives to existing ones. Figure 3 graphically shows all the steps of the RelReg lifecycle. 


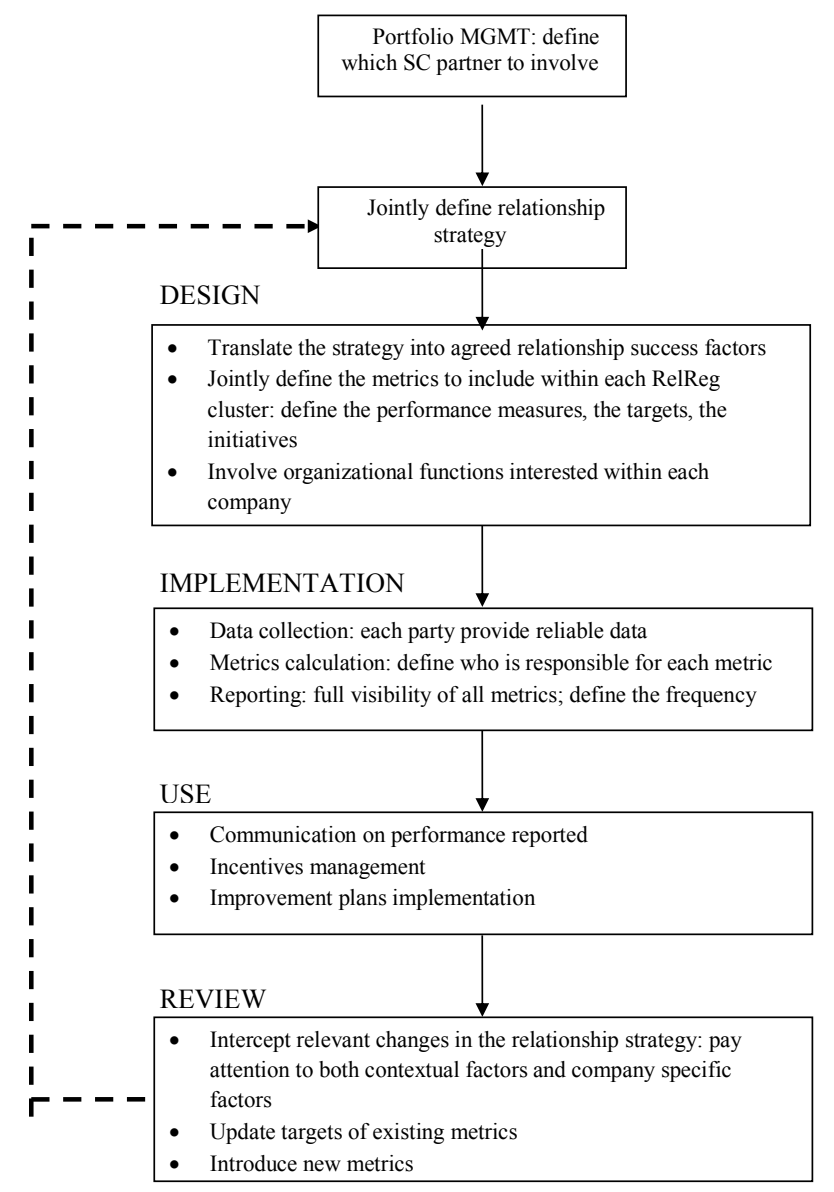

Figure 3: The RelReg lifecycle

\section{Discussion}

Extant literature does not tackle the issue of collaboratively measuring and managing external SC performance. Nevertheless this pattern is not diffused within companies: it is generally limited to a short panel of SC actors with partnership relationships and by the way not related to a structured performance measurement and management process. Each company within a SC naturally displays a far higher confidence on internally developed SCPMSs than in performance measures coming from external partners. Large companies always measure some kind of SC performance by themselves and this eventually results in a myriad of metrics flowing within a SC. These metrics often increase the distance among SC partners rather than integrate them (see Purdy et al., 1994; Purdy and Safayeni, 2000). Focusing on dyadic relationships (the elementary component of a complex SC) a recurrent phenomenon could be observed: the presence of "duplicated metrics". With "duplicated metrics" we refer to performance measurement tackling the same aspects of buyer-supplier processes or relationships, which are autonomously measured by the two parties involved. Often these metrics are computed in a slightly different way, grounding on independent data collection process led by the two companies. Each actor relies upon its own measures, thus often leading to rigid relationships and to the impossibility to carry on joint performance improvement plans (Hald and Ellegaard, 2011). Performance measures are used to fuel harsh negotiations, increase the bargaining power and develop autonomous local optimization processes (Luzzini et al., 2014). The RelReg challenges this paradigm starting from agreed relationship goals and allowing an active participation of both parties from the design to the review phase. The idea is to adopt the measurement tool to quantify the outcomes of mutual collaboration efforts, thus aiming at continuous improvement and win-win initiatives.

The RelReg adoption is with no doubts a highly time-consuming and demanding process: a partnership should be developed; a joint SCPMS should be designed finding a convergence on the metrics to be adopted; a reliable management information infrastructure should be put in place to link the two parties and allowing data collection, performance measures calculation and reporting. Investments in time and resources are needed and the benefits could be tangible only in the long run. Another element that we need to consider is that while a RelReg tackled a single buyer-supplier strategic relationship, companies interact with a lot of strategic SC partners. Then there may be a problem of integrating the RelReg with the other external SCPMS. However the RelReg could be easily transferable to other external relationships, either in an explicit formal way (other RelRegs adoption) or in an implicit way (by always referring to the goals defined in the RelReg, also when dealing with other SC partners).

\section{Conclusions, limitations and implications}

This study represents a first attempt to address the topic of buyer-supplier collaboration on mutual performance. Considering both the way it is designed and the guidelines for its implementation, use and review, the RelReg has been developed to be a referred framework that a buyer and a supplier company could follow to guide their relationship towards superior performance. 
The main limitation of this study is the lack of empirical application for the proposed framework. This paper has to be considered as a seminal work on buyer-supplier collaborative performance measurement and management. We therefore encourage both scholars and practitioners to try to implement the RelReg in a real buyer-supplier relationship in order to refine the proposed model. Another limitation of the study relies in the link between the buyer-supplier strategy and the RelReg adoption. The measurement tool naturally comes after a mapping of the relationship strategy, aimed at highlighting key goals to operationalize. Future research should tackle the issue on how to build and describe the relationship strategy and consequently shape the RelReg coherently, also challenging the performance dimensions identified, if necessary.

We deem this paper to have several managerial implications. The RelReg is supposed to be a simple and smart tool, ready to be applied by practitioners. Indeed, we have provided normative guidelines (section 4) that could support companies within the RelReg adoption process. First, we highlighted the importance of portfolio management and of buyer-supplier strategy definition as fundamental antecedents. Once the right counterpart has been chosen and strategic goals have been agreed, the RelReg could be designed by selecting key metrics within the clusters identified. Finally, providing guidelines on the implementation, use and review too, we aim at supporting practitioners all along the steps of the lifecycle.

This study is at the crossroads between external SCPMS literature and buyer-supplier relationship management literature and display theoretical contributions to both. Rather than addressing the topic from a holistic perspective like other research before (think about SCOR based framework), we propose the single dyad as the fundamental unit to tackle. Then we build a new measurement tool, which allows both parties to take an active role in the measurement and management process. Our hope is that this study may fuel a new stream of research based on buyer-supplier collaborative performance measurement and management.

\section{Reference}

Agarwal, A., Shankar, R., Tiwari, M. K. (2006), "Modeling the metrics of lean, agile and leagile supply chain: An ANP-based approach", European Journal of Operational Research, Vol. 173 No. 1, pp. 211-225.

Arzu Akyuz, G., \& Erman Erkan, T. (2010), "Supply chain performance measurement: a literature review”, International Journal of Production Research, Vol. 48 No. 17, pp 5137-5155.

Angerhofer, B. J., and Angelides, M. C. (2006), "A model and a performance measurement system for collaborative supply chains”, Decision Support Systems, Vol. 42 No. 1, pp. 283-301.

Beamon, B. M. (1999), "Measuring supply chain performance", International Journal of Operations and Production Management, Vol. 19 No. 3, pp. 275-292.

Bhagwat, R., and Sharma, M. K. (2007), "Performance measurement of supply chain management: A balanced scorecard approach", Computers and Industrial Engineering, Vol. 53 No. 1, pp. 43-

Bititci, U. S., Mendibil, K., Nudurupati, S., Garengo, P., Turner, T. (2006), "Dynamics of performance measurement and organisational culture" International Journal of Operations and Production Management, Vol. 26 No. 12, pp. 1325-1350.

Bourne, M., Mills, J., Wilcox, M., Neely, A. and Platts, K. (2000), "Designing, implementing and updating performance measurement systems", International Journal of Operations and Production Management, Vol. 20 No. 7, pp. 754-71.

Bourne, M., Neely, A., Platts, K., Mills, J. (2002), "The success and failure of performance measurement initiatives: perception of participating managers", International Journal of Operations and Production Management, Vol. 22 No. 11, pp. 1288-1310.

Bourne, M., Neely, A., Mills, J., Platts, K. (2003), "Implementing performance measurement systems: a literature review", International Journal of Business Performance Management, Vol. 5 No. 1, pp. 1-24.

Braz, R.G.F., Scavarda, L.F., Martins, R.A. (2011), "Reviewing and improving performance measurement systems: an action research", International Journal of Production Economics, Vol. 133, pp. 751-760.

Brewer, P. C. and Speh, T. W. (2000), "Using the balanced scorecard to measure SC performance", Journal of Business Logistics, Vol. 211, pp. 75-93.

Bullinger, H., Kühner, M., Van Hoof, A. (2010), "Analysing supply chain performance using a balanced measurement method", International Journal of Production Research, Vol. 40, No. 15, pp. 3533-3543. 
Cai, J., Liu, X., Xiao, Z., Liu, J. (2009), "Improving supply chain performance management: a systematic approach to analyzing iterative KPI accomplishment", Decision Support Systems, Vol. 46, pp. $512-521$.

Chae, B. (2009), "Developing key performance indicators for supply chain: an industry perspective", Supply Chain Management: An International Journal, Vol. 14 No. 6, pp. $422-8$.

Chan, F. T. S., and Qi, H. J. (2003), "Feasibility of performance measurement system for supply chain: a process-based approach and measures", Integrated Manufacturing Systems, Vol. 14, No 3, pp. 179-190.

Cho, D. W., Lee, Y. H., Ahn, S. H., Hwang, M. K. (2012), "A framework for measuring the performance of service supply chain management", Computers and Industrial Engineering, Vol. 62(3), pp. 801-818.

Cousins, P. D., Lawson, B., \& Squire, B. (2008), "Performance measurement in strategic buyersupplier relationships: the mediating role of socialization mechanisms", International Journal of Operations \& Production Management, Vol. 28 No. 3, pp. 238-258.

Giannakis, M. (2007), "Performance measurement of supplier relationships", Supply Chain Management: An International Journal, Vol. 12 No. 6, pp. 400-411.

Gunasekaran, A., Patel, C., Tirtiroglu, E. (2001), "Performance measures and metrics in a supply chain environment", International journal of operations and production Management, Vol. 21 No. 2, pp. 71-87.

Gunasekaran, A., Patel, C., McGaughey, R. E. (2004), "A framework for supply chain performance measurement”, International Journal of Production Economics, Vol. 87 No. 3, pp. 333-347.

Gunasekaran, A., Kobu, B. (2007), "Performance measures and metrics in logistics and supply chain management: a review of recent literature (1995-2004) for research and applications", International Journal of Production Research, Vo. 45 No. 12, pp. 2819-2840.

Gutierrez, D. M., Scavarda, L. F., Fiorencio, L., Martins, R. A. (2015), "Evolution of the performance measurement system in the Logistics Department of a broadcasting company: An action research", International Journal of Production Economics, Vol. 160, pp. 1-12.

Hald, S. K., Ellegaard, C. (2011), "Supplier evaluation processes: the shaping and reshaping of supplier performance", International Journal of Operations \& Production Management, Vol 31 No. 8, pp. 888-910.

Henri, J.F. (2006), "Management control systems and strategy: a resource-based perspective", Accounting, Organizations and Society, Vol. 31 No. 6, pp. 529-558,

Hesping, F. H., Schiele, H. (2015), "Purchasing strategy development: A multi-level review”, Journal of purchasing and supply management, Vol. 21 No. 2, pp. 138-150.
Ho, C. J. (2007), "Measuring system performance of an ERP-based supply chain", International journal of production research, Vol. 45 No. 6, pp. 1255-1277.

Hong, Y., and Zhong-hua, Y. (2013), "Supply Chain Dynamic Performance Measurement Based on BSC and SVM", International Journal of Computer Science Issues, Vol. 10, No. 2, pp. 271-277.

Kannan, V. R., and Tan, K. C. (2002), "Supplier selection and assessment: Their impact on busines performance", Journal of Supply Chain Management, Vol. 38 No.3, pp. 11-21.

Kaplan, R. S., Norton, D. P. (1996), "The balanced scorecard: translating strategy into action", Harvard Business Press.

Koufteros, X., Verghese, A. J., Lucianetti, L. (2014), "The effect of performance measurement systems on firm performance: A cross-sectional and a longitudinal study", Journal of Operations Management, Vol 32 No 6, pp 313-336.

Lambert, D.M., Pohlen, T.L. (2001), "Supply chain metrics", The International Journal of Logistics Management, Vol. 12, No. 1, pp. 1-19.

Li, S., Nathan, B.R., Nathan, T.S., Rao, S.S. (2005), "Development and validation of a measuremen instrument for studying supply chain management practices", Journal of Operations Management, Vol. 23, pp. 618-623.

Lohman, C., Fortuin, L., Wouters, M., (2004), "Designing a performance measurement system design: a case study", European Journal of Operational Research, Vol. 156 No. 2, pp. 267-286

Luzzini, D., Caniato, F., Spina, G. (2014), "Designing vendor evaluation systems: An empirical analysis", Journal of Purchasing and Supply Management, Vol. 20 No. 2, pp. 113-129.

Luzzini, D., Ronchi, S. (2016), "Cinderella purchasing transformation: linking purchasing status to purchasing practices and business performance", Production Planning \& Control, pp. 1-10.

Melnyk, S. A., Bititci, U., Platts, K., Tobias, J., Andersen, B. (2014), "Is performance measurement and management fit for the future?”, Management Accounting Research, Vol. 25 No. 2, pp. 173

Neely, A., Gregory, M., Platts, K. (1995), "Performance measurement system design: a literature review and research agenda", International Journal of Operations and Production Management, Vol. 15 No. 4, pp. 80-116

Neely, A. (1999), "The performance measurement revolution: why now and what next?", International Journal of Operations and Production Management, Vol. 19 No. 2, pp. 205-228

Nudurupati, S. S., Bititci, U. S., Kumar, V., Chan, F. T. (2011), "State of the art literature review on performance measurement", Computers and Industrial Engineering, Vol. 60 No.2, pp. 279-290. 
Purdy, L., Astad, U. and Safayeni, F. (1994), "Perceived effectiveness of automotive supplier evaluation process", International Journal of Operations and Production Management, Vol. 14 No. 6, pp. 91-103.

Purdy, L., and Safayeni, F. (2000), "Strategies for supplier evaluation: a framework for potential advantages and limitations", IEEE Transactions on Engineering Management, Vol. 47 No. 4, pp. 435-443.

Qi, Y., Zhao, X., Sheu, C., (2011), "The impact of business strategy and supply chain strategy on business performance: the role of environmental uncertainty", Decision Sciences, Vol. 42, No.2, pp. 371-389.

Ramanathan, U., Gunasekaran, A., Subramanian, N. (2011), "Supply chain collaboration performance metrics: a conceptual framework", Benchmarking: An International Journal, Vol. 18 No. 6, pp. 856-872.

Rice, J. B., Hoppe, R. M. (2001), Supply chain vs supply chain: the hype and the reality, Supply Chain Management Review, Vol. 5 No. 5, pp. 46-54.

Sellitto, M. A., Pereira, G. M., Borchardt, M., da Silva, R. I., Viegas, C. V. (2015), “A SCOR-based model for supply chain performance measurement: application in the footwear industry", International Journal of Production Research, (ahead-of-print), 1-10.

Simpson, P.M., Siguaw, J.A. and White, S.C. (2002), "Measuring the performance of suppliers: an analysis of evaluation processes", Journal of Supply Chain Management, Vol. 38 No. 1, pp. 2941.

Van Hoek, R. (1998), "Measuring the unmeasurable - measuring and improving performance in the supply chain, Supply chain management, Vol. 3, No. 4, pp. 187-192.

Zhang, D. (2006), "A network economic model for supply chain versus supply chain competition", Omega, Vol. 34 No. 3, pp. 283-295. 